\title{
An approach to computerized preliminary design procedure of mid-size superyachts from hull modeling to interior space arrangement
}

\author{
Jong-Ho Nam ${ }^{1}$, Dong-Ham Kim² and Ho Jin Lee ${ }^{1}$ \\ ${ }^{I}$ College of Ocean Science and Technology, Korea Maritime University, Busan, Korea \\ ${ }^{2}$ Wingship Technology, Daejon, Korea
}

\begin{abstract}
A concept of preliminary design for mid-size superyachts is explored. First, the profile of a superyacht is interactively designed with the help of freeform curve functionality and graphical user interface (GUI) based interaction. The hull form is then constructed using major characteristic curves such as design waterline, deck sideline, and sections in addition to the predefined profile curve. After exterior hull modeling is done, the arrangement of significant interior spaces of all decks is carried out. A genetic algorithm is exploited to find a space arrangement by considering space fitness values, space proximity, and stairs connectivity of relevant spaces. A goal of the paper is to offer a step-by-step procedure for superyacht design from scratch or when initial information is not sufficient for complete design. For this purpose, a GUI based superyacht design system is developed. This design approach is expected to help users interactively design mid-size superyachts.
\end{abstract}

KEY WORDS: Superyacht; CAD; Modeling; Genetic algorithm; Interior space arrangement.

\section{INTRODUCTION}

Superyacht industry is a high added-valued market and its potential buying power has grown steadily. It is not new but recently has drawn attention as an emerging item in shipbuilding industries. Unlike other commercial vessels, the superyacht design emphasizes style and luxury, even though engineering is still an important aspect. Superyachts have been traditionally built in European countries where the selling amount and employment in middle-sized shipyards have been on the rise.

The size of superyachts has increased. Recent reports reveal that superyachts of at least 24 meters have dominated the market. As of 2006, the superyacht market share shows that Italy stands at the top with $37.8 \%$, followed by United States with $12.4 \%$, Netherlands and United Kingdom with $7 \sim 8 \%$, and then Germany and New Zealand (Kim, 2008). Although Korean shipbuilding industry has basic technology, it falls behind in the field of various supplementary equipment and luxurious interior design.

Superyachts are relatively new and undeveloped in regards to design and technology. Research results of their design and construction are seldom available, which makes it difficult to make strides with superyacht design. Preliminary work has been published by Nam et al. (2007) but the content was limited to partial modeling of a superyacht and did not deal with a comprehensive design. In comparison to research

Corresponding author: Jong-Ho Nam

e-mail:.jhnam@hhu.ac.kr on exterior design of superyachts, researches on interior design of superyachts are scarcer. No guideline on space arrangement has been known to the authors except the analysis of current layout (Lee and Byun, 2007). Most interior designs are executed by some experts in advanced shipbuilding countries. Therefore, a preliminary guideline for the superyacht design is strongly desired to help the designer find a good starting point. Even the experts can verify their design using the guideline suggested here.
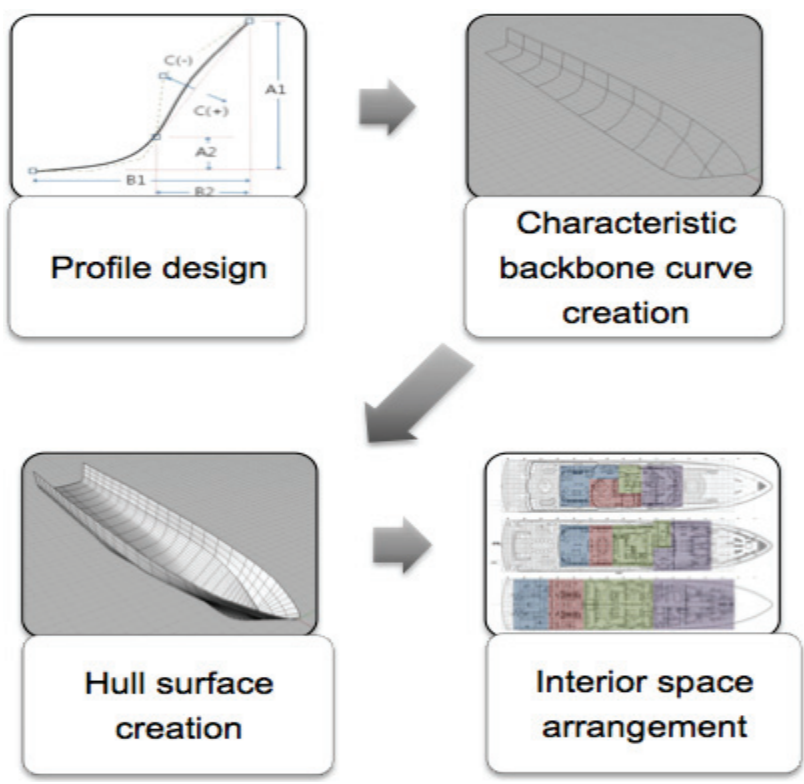

Fig. 1 Overall design procedure. 
This paper presents the overall guide to the hull form modeling of superyachts. An algorithm that facilitates the interior space arrangement is implemented. The overall design flow is depicted in Fig.1.

\section{DETERMINATION OF PROFILE CURVE}

One way to generate the hull form is to build up a surface over a set of backbone curves. The hull form of the superyacht is not easy to standardize because its shape is very unique and different from that of conventional vessels. In this research, the profile curve is selected as a key curve that characterizes the outline of hull form. The purpose of designing with the profile curve is to consider the engineering as well as the aesthetic point of view.

As superyachts have their own characteristic shapes and are different from each other, it is known to be difficult to directly design the whole profile curve. As a remedy, it is suggested that the profile curve be divided into the zones. Each zone is designed separately to be merged later.

The profile curve is defined by the NURBS representation (Piegl and Tiller, 1995; Rogers, 2001). The piecewise profile curve in each zone is designed using the parameters that characterize the curve and those piecewise curves are later merged into a single profile curve by imposing the necessary continuity across neighboring zones. Profile shape can be modified by interactively changing the parameter values. To make the design process more intuitive, the graphical user interface that enables the construction as well as the modification of the existing shape is constructed. Fig.2 shows an example of the dialog box that manipulates five parameters to design a flat type bow. The five parameters consist of two pairs of control points in $x z$ plane and a scalar factor $C$ that controls the fullness of stem.

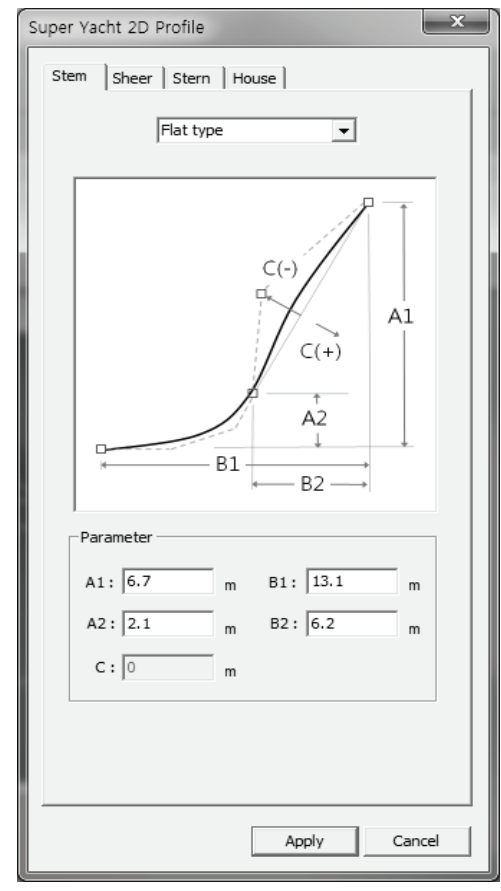

Fig. 2 Dialog for stem design.

\section{HULL SURFACE MODELING}

In general, the three-dimensional geometric data of a ship is necessary in order to model the hull form. Unfortunately, these data for superyachts are not easy to obtain and, if available, it is not easy to use conventional hull variation techniques that treat the existing ship as a mother ship, because of the unique and special hull shape of superyachts. Bearing in mind that our goal is to suggest a guideline for the overall design of a superyacht rather than to perform a detailed design of hull form, we carry out a direct hull form modeling without using the concept of a mother ship.

A modeling technique presented in this research is to interactively determine the major characteristic curves and then to generate an outer hull surface based on those major curves. This technique is not new and the concept is similar to that of lofting, sweeping, or skinning, all of which are popular surface generation techniques used in modern CAD systems (Woodward, 1988; Piegl and Tiller, 1995). Preparing adequate characteristic and spine curves in advance is necessary to obtain accurate results from those techniques,.

One of the concerns in regards to generating a correct hull form is how to determine the 'appropriate' characteristic curves from a superyacht that may contain very eccentric shape in stern or stem. Commercial CAD packages are utilized to model the major curves and the hull surface. High level packages such UGNX (2008) and solidThinking (2009) are used to confirm the possibility of skinning process from prepared major curves, while the popular Rhino3D (2009) is adopted to generate final surfaces.

In this work, the characteristic spine curves are a design waterline, a deck sideline, and multiple sections. If the stern has sharply corners or unnatural geometric shape, however, it is recommended to include more curves that support the skinning process.

\section{Determination of design waterline and deck sideline}

The waterline at draft and the deck sideline are significant factors in determining the hull form. In most ships, even in superyachts, those two curves are assumed to be similar in shape and thus, the same modeling technique can be applied to them. This assumption is still valid in this work but the designer should be entitled to greater freedom without being restricted by the assumption.

Determining the waterline at draft, also known as design waterline, can be categorized as two methods: the one that uses the numerical values from hydrostatic and/or hydrodynamic calculations, and the other that emphasizes the stylish shape. The former method uses the functional values such as area, longitudinal center of floatation (LCF), and entrance angle of waterline at draft. The control points of the curve representing the waterline are determined so that the given values are satisfied by the final curve. On the other hand, it is more natural to stress the style of superyachts on the basis of minimal geometric requirements, such as necessary spaces for equipment and rooms. In this work, the latter approach is adopted to generate more smooth and natural waterline at draft. 
Technically, an arbitrary, rough NURBS curve that approximates the waterline is prepared in advance and its control points are interactively adjusted to converge the final shape. Unfortunately, moving a set of control points together to reach the desired shape by satisfying specified values is tricky and inefficient. The approach introduced in this research is to select a minimal set of design parameters that represent the waterline and to manipulate the parameters to generate the desired waterline, following the same concept used in the profile design.

If the user demands certain functional values such as waterplane area or LCF, an interactive algorithm computes the area and LCF numerically at each design stage until the satisfactory values are fulfilled. The similar problem that determined the design parameters of the area and the longitudinal center of buoyancy in a commercial vessel was introduced by the author (Nam and Parsons, 2000). Rather than applying the interactive design approach, the problem was formulated into an optimization problem and was solved numerically. This numerical approach can be applied to the current problem if the functional values are available in advance, which is not the case of superyacht design.

\section{Determination of sectional shape}

To determine a hull form, its geometric information should be available in advance. A traditional and convenient way is to use the two dimensional information, called sections, at key stations. Sections usually satisfy the engineering requirements imposed by a naval architect, such as area, center of mass, and other geometric constraints. Thus it is imperative to provide the accurate information of sections to generate a desired hull form.

Three characteristic curves, profile, waterline at draft, and deck sideline, are used to design sections. As seen in Fig.3, the profile determines the vertical position of the section bottom while the waterline at draft and the deck sideline impose geometric constraints horizontally. A section must intersect with those three curves.

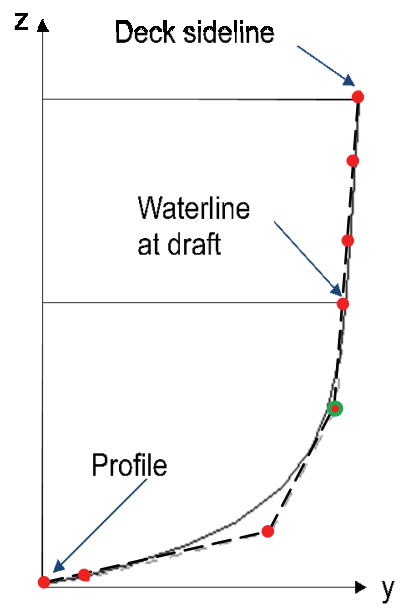

Fig. 3 Intersection of section with profile, waterline at draft, and deck sideline.
A section can be determined numerically by the optimization technique as well. The problem is converted into a minimization problem that determines the section based on the required functional values. A common and reasonable approach is to use the section area and the vertical center of floatation (VCF), as formulated in Eq.(1):

Minimize $f(X)$ subject to $g(X)$

where $X$ is a vector of control points of a section curve to be determined, $f(X)$ is the scalar value represented in sum of the differences between desired and obtained values of area and $\mathrm{VCF}$, and $g(X)$ is a set of constraints used to assign the geometric shape of the section. With the two design parameters, $f(X)$ is expressed as:

$$
f(X)=w_{1}\left(A_{d}-A_{a}\right)^{2}+w_{2}\left(V_{d}-V_{a}\right)^{2}
$$

where $w_{i}$ is the weighting factors controlling the contribution of the two parameters, $A$ and $V$ represent the area and VCF respectively, and subscript $d$ denotes desired and $o$ obtained.

A weakness of the above formulation is that the designer must have an idea as to what the values of the section area and VCF are in advance. Conventional commercial ships are designed from the offset table and thus the geometric information and other functional values are available from simple and direct calculations. However, this kind of scenario may not go along with superyacht design, as the hull form of a superyacht is likely to directly be designed from stylist's sketches in some cases. Therefore, dealing with the area or VCF in the earlier design stage is not practical. Fortunately, as suggested in the profile and other characteristic curves' design processes, it may be plausible to interactively design the sections with the emphasis on styling aspects. In this work, control points are adjusted to obtain a desired section with a set of geometric constraints that restrict the shape of a section. Nonetheless, an option to use the area and VCF as constraints should not be neglected. A dialog that determines a section is depicted in Fig.4.

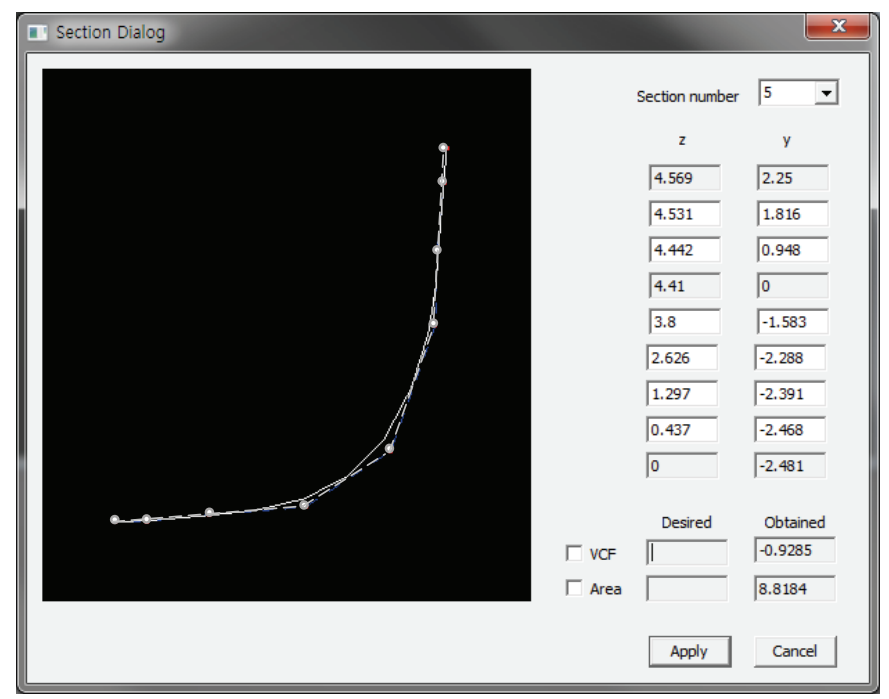

Fig. 4 Dialog for interactive section design. 


\section{Construction of hull surface by skinning technique}

With the characteristic curves and sections, the hull form of a superyacht is generated. Two important factors considered in the hull form generation are the number of sections and their positions. The more sections we have, the more accurate hull form is obtained in general. However, more sections sometimes result in a wiggly shape. On the other hand, lesser sections cannot represent the hull form properly, and thus, the resulting hull form is inaccurate. The positions of sections are hard to generalize because they significantly influence the shape of the final hull form. Therefore dealing with the appropriate number of sections and their positions should be seriously considered. Unfortunately, no analytical solution that computes the number of sections and their positions is known to the authors.

In our work, an indirect method to determine the number of sections and positions interactively through a GUI system is introduced. From the repeated practice of the surface skinning technique of CAD systems, rough estimation can be offered to enhance the efficiency of skinning process. Ten sections are shown to be sufficient enough to generate a smooth hull form, as illustrated in Fig.5.

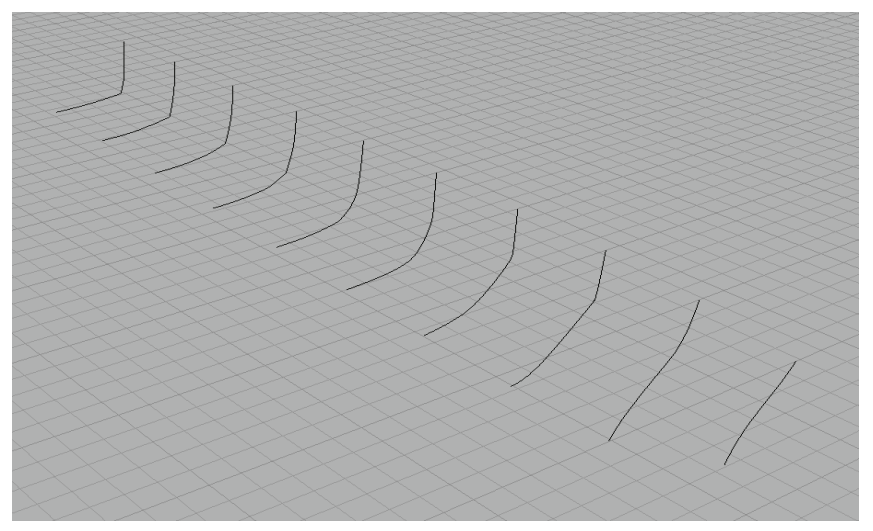

Fig. 5 Sections at particular stations.

The hull form constructed using a sweeping function of Rhino3D (2009) is shown in Fig. 6.

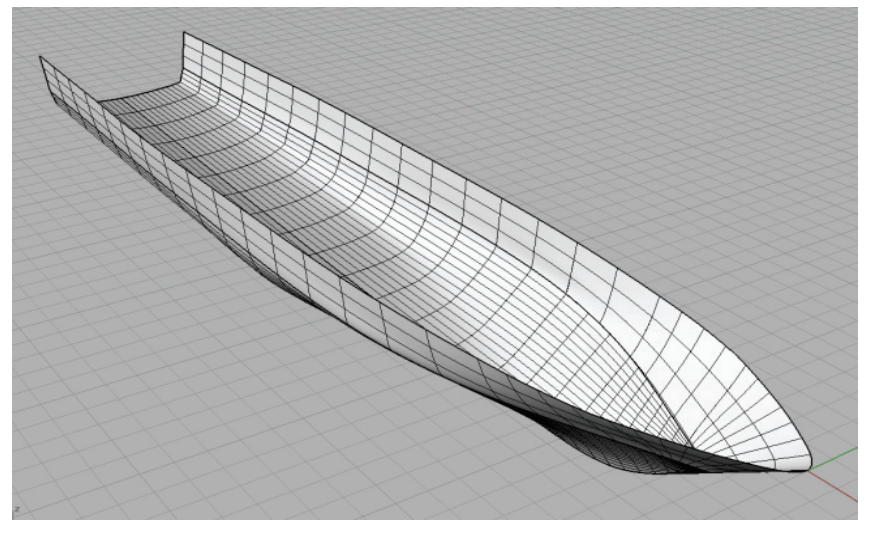

Fig. 6 Swept hull form of superyacht.

\section{AUTOMATIC GENERATION OF INTERIOR SPACE ARRANGEMENT}

Many publications regarding the general space allocation have been released. Nehrling (1985) proposed a way to determine the general arrangement of a ship using fuzzy set theory. This paper advocated a method that evaluated and compared goals and constraints. Jo and Gero (1998) from the University of Sydney proposed using a genetic algorithm to solve allocation problems. They formulated a design problem with $n$ number of spaces. An approach using a modified genetic algorithm was introduced by Lee et al. (2002) who tried to meet the need of better space utilization. Recently, an agent-based approach to allocate spaces was discussed by Daniels and Parsons (2006).

The interior of superyachts is heavily dependent on the purpose the customer has in mind, which, in turn, can be influenced by the customer's personality or culture. It has been investigated that there exists no specified formula in designing the interior spaces. The interior is designed by an experienced designer usually after the length of a superyacht is decided. For a novice or inexperienced worker, this would be a difficult task.

An algorithm that determines a layout of interior spaces is developed based on the fact that the layout of current interior spaces can be standardized or formulated up to a certain level by the analysis of experts' design experiences. The algorithm does not completely replace the experts' design knowhow's but at least it suggests a guideline to initial layout of interior spaces.

\section{Classification of interior spaces and stairs}

The first task was to collect the layout of interior spaces of currently operating superyachts. Many data of general arrangement were obtained from the $48^{\text {th }}$ Genoa International Boat Show (GIBS, 2008) and from rental companies' web pages. Previous research on the space elements of superyachts done by Lee and Byun (2007) was referenced as well.

The design concept of the interior layout of superyachts varies depending on the ship size. A common interior layout that covers all range of ship's length is not only unavailable but also undesirable because of the emphasis on the aesthetic design. From the analysis of wide range of layout samples, a superyacht of 50 meters was chosen because of their abundance in amount and their variety of interior spaces. The design concept can be readily extended to other lengths.

Superyachts of 50 meters consist of four decks from bottom to top: lower deck, main deck, upper deck, and sun deck. Thirteen vessels are investigated and their space arrangements are summarized in Table 1 . The acronyms are explained in Table 2 where typical spaces located in each deck are tabulated. They show the similar arrangement pattern as expected.

WESTPORT64 (2007) is selected as a sample model in this work. Its interior space arrangement is shown in Fig.7, categorized by different colors. Some neighboring spaces are 
hard to discern due to their overlap. Sometimes they join in a stepwise fashion that makes it difficult to represent a space in a simple rectangular polygon. The spaces near the stern and the stem are not included because of their irrelevance to the space arrangement.

Table 1 Various space arrangement in superyachts of 50 meters.

\begin{tabular}{|c|c|c|c|c|}
\hline Superyacht & $\begin{array}{c}\text { Lower } \\
\text { deck }\end{array}$ & $\begin{array}{c}\text { Main } \\
\text { deck }\end{array}$ & $\begin{array}{c}\text { Upper } \\
\text { deck }\end{array}$ & $\begin{array}{c}\text { Sun } \\
\text { deck }\end{array}$ \\
\hline WESTPORT164 & $\begin{array}{c}\text { P TB ER } \\
\text { GR CS }\end{array}$ & $\begin{array}{c}\text { AD S DR } \\
\text { G MR FD }\end{array}$ & $\begin{array}{c}\text { AD VL } \\
\text { VR PH }\end{array}$ & B FB \\
\hline Benetti LATINOU & $\begin{array}{c}\text { P TB ER } \\
\text { GR CS }\end{array}$ & $\begin{array}{c}\text { AD S DR } \\
\text { G MR FD }\end{array}$ & $\begin{array}{c}\text { AD VL } \\
\text { VR L PH }\end{array}$ & FB \\
\hline SUNSEEKER4M & $\begin{array}{c}\text { P TB ER } \\
\text { GR CS }\end{array}$ & $\begin{array}{c}\text { AD S DR } \\
\text { G MR FD }\end{array}$ & $\begin{array}{c}\text { AD VL } \\
\text { L PH }\end{array}$ & FB \\
\hline ISA 470,480,500 & $\begin{array}{c}\text { P TB ER } \\
\text { GR CS }\end{array}$ & $\begin{array}{l}\text { AD S DR } \\
\text { G MR FD }\end{array}$ & $\begin{array}{c}\text { AD VL } \\
\text { L PH }\end{array}$ & FB \\
\hline TIMMERMAN & $\begin{array}{c}\text { P TB ER } \\
\text { GR CS }\end{array}$ & $\begin{array}{c}\text { AD S DR } \\
\text { G MR FD }\end{array}$ & $\begin{array}{c}\text { AD VL } \\
\text { L PH }\end{array}$ & FB DR \\
\hline G MR FD & $\begin{array}{c}\text { AD VL } \\
\text { L PH }\end{array}$ & FB \\
\hline LADY MICHELLE & $\begin{array}{c}\text { P TB ER } \\
\text { GR CS }\end{array}$ & $\begin{array}{l}\text { AD S DR } \\
\text { G MR FD }\end{array}$ & $\begin{array}{c}\text { AD VL } \\
\text { L PH }\end{array}$ & B FB \\
\hline INEVITABLE & $\begin{array}{c}\text { P TB ER } \\
\text { GR CS }\end{array}$ & $\begin{array}{l}\text { AD S DR } \\
\text { G MR FD }\end{array}$ & $\begin{array}{c}\text { AD VL } \\
\text { L PH }\end{array}$ & B FB \\
\hline LOHEGRIN & $\begin{array}{c}\text { P CS ER } \\
\text { GR CS }\end{array}$ & $\begin{array}{l}\text { AD S DR } \\
\text { G MR FD }\end{array}$ & $\begin{array}{c}\text { AD VL } \\
\text { L PH }\end{array}$ & B FB \\
\hline MINE GAMES & $\begin{array}{c}\text { TB CS ER } \\
\text { GR CS }\end{array}$ & $\begin{array}{l}\text { AD S DR } \\
\text { G MR FD }\end{array}$ & $\begin{array}{c}\text { AD VL } \\
\text { L PH }\end{array}$ & FB \\
\hline ALEXANDRA & $\begin{array}{c}\text { P TB ER } \\
\text { GR CS }\end{array}$ & $\begin{array}{l}\text { AD S DR } \\
\text { G VR FD }\end{array}$ & $\begin{array}{c}\text { AD MR } \\
\text { L PH }\end{array}$ & FB \\
\hline
\end{tabular}

Table 2 Typical space allocations at each deck.

\begin{tabular}{|c|l|}
\hline Deck & \multicolumn{1}{|c|}{ Allocated spaces } \\
\hline Sun deck & Fly bridge(FB), Boat(B) \\
\hline Upper deck & $\begin{array}{l}\text { Pilot house(PH), Lobby(L), VIP room(VR), } \\
\text { VIP lounge(VL), Aft deck(AD) }\end{array}$ \\
\hline Main deck & $\begin{array}{l}\text { Fore deck(FD), Master room(MR), Galley(G), } \\
\text { Salon(S), Dining room(DR), Aft deck(AD), } \\
\text { VIP room(VR) }\end{array}$ \\
\hline Lower deck & $\begin{array}{l}\text { Crew space(CS), Guest room(GR), Engine } \\
\text { room(ER), Tender boat(TB), Platform(P) }\end{array}$ \\
\hline
\end{tabular}

The traffic lines of passengers and crew are determined by the respective locations of spaces and stairs. Passengers' privacy is regarded as an important factor and thus the spaces should be allocated so that the passengers and crew encounter one another less frequently. In this case, the positions of stairs can be made by considering the desired traffic lines. All stairs residing in a superyacht are labeled in regards to their respective connection to a certain space, summarized in Table 3.

\section{Application of genetic algorithm to space arrangement}

To designate spaces and stairs, the connecting information between the two entities must be identified through the analysis of stairs with respect to their usage and locations. This problem can be formulated as an optimization problem and the genetic algorithm (Goldberg, 1989) is used to solve the problem here.

Table 3 Usage of stairs.

\begin{tabular}{|c|l|}
\hline Stairs & \multicolumn{1}{|c|}{ Usage } \\
\hline Crew & $\begin{array}{l}\text { Connect crew spaces and galley. Exclusively used } \\
\text { by crew }\end{array}$ \\
\hline Guest & $\begin{array}{l}\text { Connect guest rooms and galley or salon. } \\
\text { Exclusively used by guests }\end{array}$ \\
\hline Engine & Connect main deck and engine room \\
\hline Platform & Connect main deck and platform / tender boat area \\
\hline Galley & $\begin{array}{l}\text { Connect galley, pilothouse, and lounge. } \\
\text { Exclusively used by crew }\end{array}$ \\
\hline Exterior & $\begin{array}{l}\text { Connect main deck and upper deck. Usually } \\
\text { located near aft deck }\end{array}$ \\
\hline Sun & $\begin{array}{l}\text { Connect upper deck and Sun deck. Usually located } \\
\text { near aft deck }\end{array}$ \\
\hline Fly & $\begin{array}{l}\text { Connect fly bridge, pilot house, lounge or VIP } \\
\text { lounge }\end{array}$ \\
\hline
\end{tabular}

Each deck is represented by 440 equal sized grids and each space is supposed to occupy some grids, that is, specific area. The space arrangement of WESTPORT164 shown in Fig.7 is simplified to rectangular shapes as depicted in Fig.8. The purpose of simplifying the space arrangement is to figure out a possible arrangement of interior spaces without respect to every detail. A detailed and more accurate arrangement can be tailored from the result of our work by an expert, as suggested in the beginning.

The simple genetic algorithm is adopted to solve the arrangement problem. For the faster performance, tournament-crossover selection is used (Mahfound, 2000). This selection is known to yield good results as long as the objective function is simple and the constraints are not complex. The search proceeds from the lower deck to the sun deck step by step. If the stopping criteria are met at each deck, 
the algorithm jumps into next deck. 3000 generation run at each deck is set as a failure condition and the algorithm goes back to the previous deck to resume the search. A final result is obtained when the algorithm stops at the sun deck without failure.

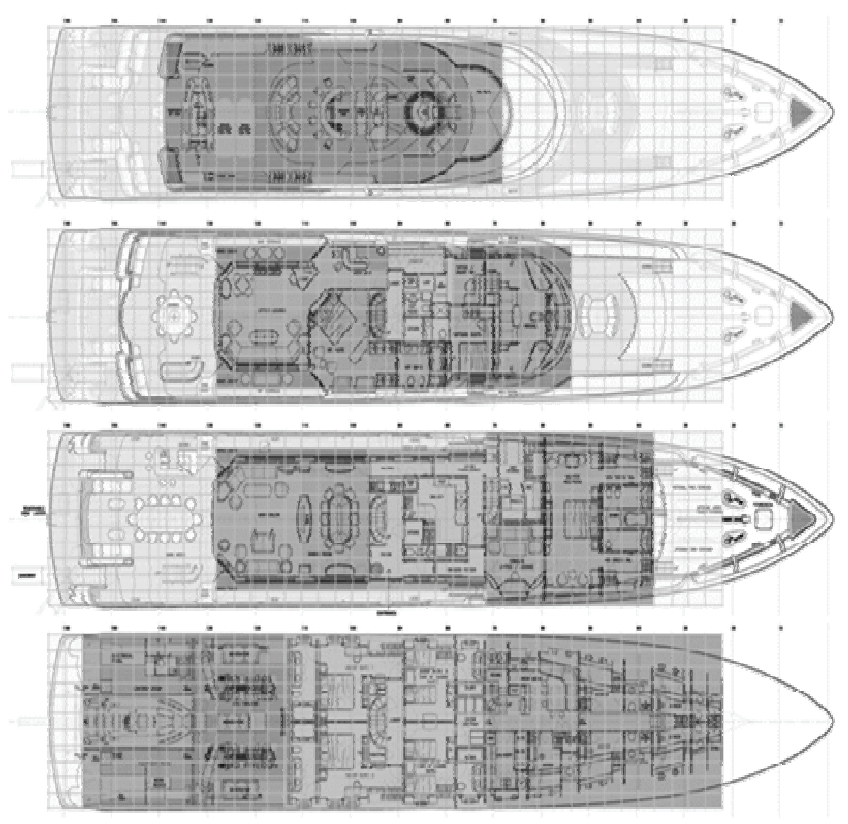

Fig. 7 Space arrangement of WESPORT164 (2007).

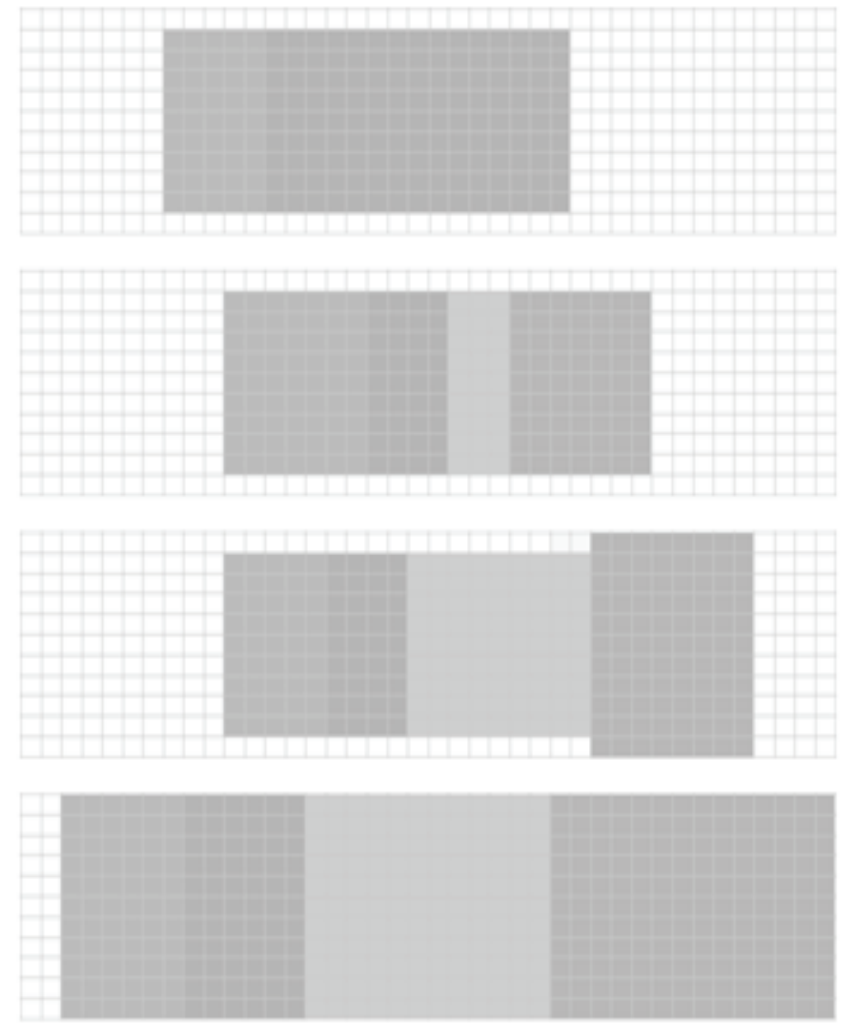

Fig. 8 Initial layout of simplified space elements.

\section{Assessment criteria for space fitness}

For the application of the genetic algorithm to finding an space arrangement, reasonable design criteria are necessary. Hybrid assessment criteria that consider both the current layout of existing superyachts and the new design philosophy provided by the designer are introduced.

\section{Criterion 1: Fitness value for spaces}

To evaluate the fitness of a specific space at a deck, its location is quantified with the help of interior design experts and collected layout data. Those values are listed in Table 4. The region (1) is close to the stern while (4) to the stem. The values range from 1 to 10 and the higher the value is, the better fit that location is for the space element. For example, the space for a tender boat has the highest fitness value when it is located close to stern at the lower deck, as it is normally released to the water behind the hull.

\section{Criterion 2: Ratio of neighboring spaces in each deck}

The second assessment criterion is the area of each space element. Each space is represented as the area ratio at each deck. The lower and upper bounds for a space are derived from the collected data and the knowledge of experts. The area of each space, represented as the number of grids, must be within the bounds. These bounding values are can be changed based on the owner's request and hence, a different space arrangement can result. Space area ratios at the lower deck, for instance, are illustrated in Fig.9.

Table 4 Quantification of each space element at a certain position.

\begin{tabular}{|c|c|cccc|}
\hline \multicolumn{1}{|c|}{} & & 1 & $(2)$ & $(3$ & 4 \\
\hline \multirow{5}{*}{ Upper deck } & L & 6 & 8 & 10 & 3 \\
& PH & 1 & 3 & 5 & 10 \\
& VL & 10 & 8 & 6 & 1 \\
& MR & 8 & 8 & 6 & 3 \\
& VR & 7 & 10 & 6 & 3 \\
\hline \multirow{5}{*}{ Main deck } & S & 10 & 7 & 7 & 3 \\
& DR & 7 & 10 & 7 & 3 \\
& G & 3 & 8 & 10 & 3 \\
& MR & 1 & 3 & 8 & 10 \\
& VR & 1 & 3 & 6 & 8 \\
\hline \multirow{5}{*}{ Lower deck } & TB & 10 & 3 & 8 & 1 \\
& ER & 8 & 10 & 3 & 1 \\
& GR & 1 & 8 & 10 & 6 \\
& CS & 1 & 3 & 6 & 10 \\
\hline
\end{tabular}




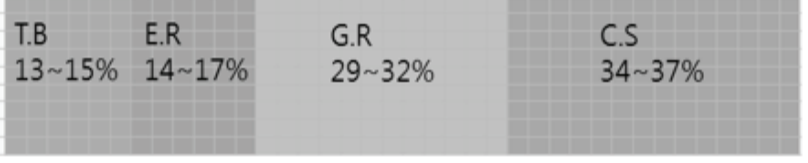

Fig. 9 Range of space occupancy in lower deck.

\section{Criterion 3: Relationship between spaces and stairs}

The fitness of stair's location is the third assessment criterion. Stairs are important as they provide the traffic line across decks. Convenient and practical space arrangement is possible when an appropriate stair connects spaces.

The typical connectivity relation of stairs is shown in Fig.10. Stairs are indicated as arrows across decks. The condition must be met within the developed algorithm.

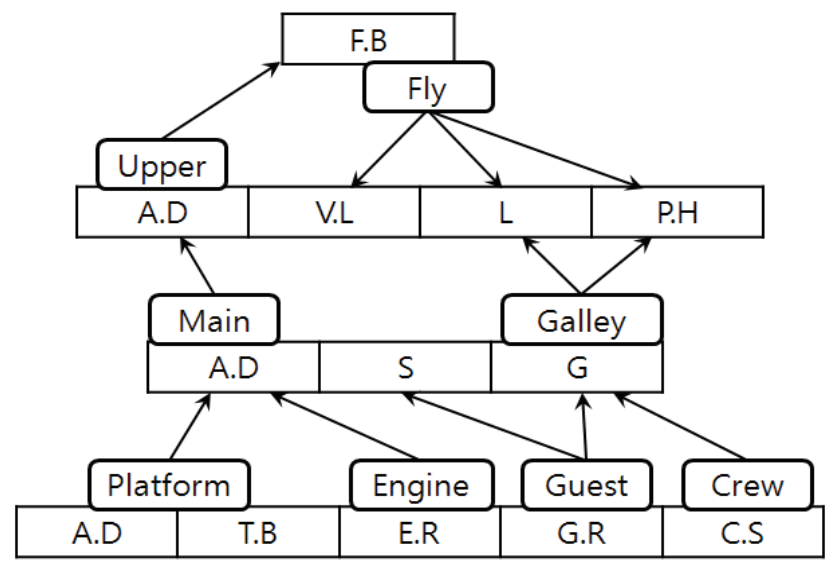

Fig. 10 Connectivity relationship of spaces through stairs.

\section{GUI based interior space arrangement system}

An interior design system for space arrangement is developed. It uses the genetic algorithm and the three assessment criteria to derive possible space arrangements. The system is based on microsoft foundation class (MFC) and the graphic user interface to enable an interactive design procedure.

On the dialog of the system, the user simply assigns the area ratio of all spaces. The system starts the search based on the assessment criteria built in the system. Searching process is monitored in real-time by displaying each result at a generation on the screen. The search starts from the lower deck and stops when the assessment criteria are satisfied up to the sun deck. Fig.11 shows an arrangement result. Arranged spaces are represented in different colors. Pairs of black grids are stairs but not their size but their location matters here. It takes averagely about 3 minutes to generate an arrangement with the current computing power.

It should be stressed that the arrangement resulting from the developed system needs to be reviewed by the designer. For more practical and desirable results, a tuning process by the expert is strongly recommended.

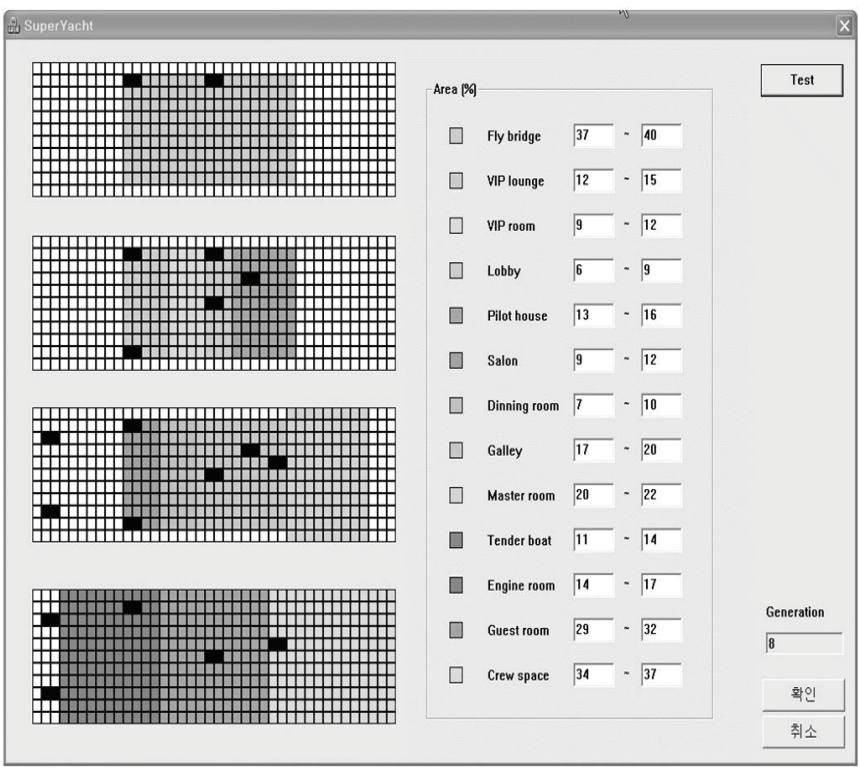

Fig. 11 A result of space arrangement with stairs.

\section{CONCLUSIONS}

Research on the hull modeling and interior space arrangement was carried out to provide a background of the preliminary superyacht design. A computerized design system for hull modeling and space arrangement of superyacht was developed.

A superyacht is first characterized by its profile and the profile is divided into separate zones for detailed modeling. NURBS representation is utilized to model characteristic curves, such as waterline at draft, deck sideline, and sections. They are interactively designed to give more freedom to the designer. A hull surface is constructed using a skinning technique available in most commercial CAD systems.

Interior spaces are identified by their usage and locations. Three assessment criteria that judge the fitness of each space at a certain location are established. The genetic algorithm is adopted to search possible space allocation.

Superyachts are relatively new and thus, neither engineering data nor accumulated design practice are readily available. The developed design system will serve a fundament design aid tool, especially for the beginners, in the field of superyacht design that has been dominated by a small number of experienced designers. It is believed that the develop system can contribute to the further superyacht design field by offering a fundamental and basic design guideline.

\section{ACKNOWLEDGMENTS}

The article was a part of a Specific Fundamental Research Project (R01-2006-000-10541-0) sponsored by the National Research Foundation of Korea. The authors are grateful for its generous financial support. 


\section{REFERENCES}

Daniels, A. and Parsons, M.G., 2006. An agent based approach to space allocation in general arrangements, 9th International Marine Design Conference, Ann Arbor, Michigan, U.S.A.

GIBS, 2008. Genoa International Boat Show. http://www.genoaboatshow.com

Goldberg, D.E., 1989. Genetic Algorithms in Search, Optimization, and Machine Learning, $1^{\text {st }}$ Ed, AddisonWesley publishing, Inc.

Jo, J. and Gero, J., 1998. Space layout planning using an evolutionary approach, Artificial Intelligence in Engineering, 12, pp.149-162

Kim, J.K., 2008. Prospect of World Ocean Industry and Growth of Superyacht Market. Review of South Region Era, Research Institute for Development of Kyungnam Province, 3, pp.36-45.

Lee, H.S. and Byun, L.S., 2007. A Study on Space Arrangement and Interior Space Division of Superyachts, Journal of Korean Institute of Interior Design, Vol.6, No.2, pp.224-231.

Lee, K.Y. Han, S.N. and Roh, M.I., 2002. Optimal Compartment Layout Design for a Naval Ship Using an Improved Genetic Algorithm, Marine Technology, 39(3), pp.159-169.
Mahfound, S., 2000. Niching Method, Evolutionary Computation 2: Advanced Algorithms and Operators. Institute of Physics Publishing, pp.87-92.

Nam, J-.H. and Parsons, M.G., 2000. A Parametric Approach for Initial Hull Form Modeling Using NURBS Representation, Journal of Ship Production, 16(2), pp.76-89.

Nam, J-.H. Hyun, B.S. Kim, T.Y. and Kim, D.H., 2007. Analysis of Hydrodynamic Performance and Establishment of Modeling Technique for Determination of Preliminary Hull Form of Superyachts. Journal of the Society of Naval Architects of Korea, 44(4), pp.451-458,

Piegl, L. and Tiller, W., 1995. The NURBS Book, Springer.

Rogers, D.F., 2001. An Introduction to NURBS with Historic Perspective, Academic Press.

Rhino3D, 2009. www.rhino3d.com, Version 4.0. Robert McNeel \& Associates.

SolidThinking, 2009. www.solidthinking.com, Version 8.0, solidThinking Inc.

UGNX, 2008. www.plm.automation.siemens.com, Version 4.0, Siemens PLM Inc.

WESTPORT164., 2007. www.westportyachts.com

Woodward, C.D., 1988. Skinning techniques for interactive B-spline surface interpolation. Computer-Aided Design, 20(8), pp.441-451. 